\title{
ANÁLISE DA GESTÃO DO GLICEROL: RISCOS E OPORTUNIDADES SOBRE SUA DESTINAÇÃO FRENTE À LACUNA NORMATIVA E ASPECTOS SUSTENTÁVEIS ${ }^{1}$
}

\author{
Juliana Chiaretti Novi ${ }^{2}$ \\ Sonia Valle Walter Borges de Oliveira ${ }^{3}$ \\ Alexandre Pereira Salgado Junior ${ }^{4}$ \\ Marcio Mattos Borges de Oliveira ${ }^{5}$
}

http://dx.doi.org/10.1590/1413-2311.223.85712

\section{RESUMO}

O Programa Nacional de Produção do Biodiesel (PNPB) buscou difundir 'sustentabilidade' com a implantação do biodiesel na matriz energética brasileira, pressupondo-se uma adequada gestão de seus resíduos. Dentre eles, há o glicerol, que foi desconsiderado, inclusive, pela Política Nacional de Resíduos Sólidos (PNRS). Seu descarte ou uso indevido nas indústrias químicas ou alimentícias pode causar problemas à saúde da população. Neste âmbito e interdisciplinarmente, o objetivo deste estudo foi analisar riscos e oportunidades sobre a destinação do glicerol frente à lacuna normativa e aos aspectos sustentáveis. Trata-se de um estudo de múltiplos-casos com metodologia qualitativa e aplicação do software Maxqda ${ }^{\circledR}$ para análise de conteúdo. Os resultados apontam algumas alternativas de destinação, mas que constituem modos fragilizados por falta de informações e regulamentação. Identifica-se tal fragilidade, principalmente, pela transferência de responsabilidade dos grandes produtores a terceiros em relação à destinação do glicerol e,

\footnotetext{
${ }^{1}$ Recebido em 09/08/2018, aprovado em 20/10/2018.

${ }^{2}$ Universidade de São Paulo - FEA-RP; São Paulo - SP (Brasil) - juliananovi@alumni.usp.br

${ }^{3}$ Universidade de São Paulo - FEA-RP; São Paulo - SP (Brasil) - $\underline{\text { soniavw@terra.com.br }}$

${ }^{4}$ Universidade de São Paulo - FEA-RP; São Paulo - SP (Brasil) - asalgado@usp.br

${ }^{5}$ Universidade de São Paulo - FEA-RP; São Paulo - SP (Brasil) - $\underline{\text { mmattos@usp.br }}$
} 
sobretudo, desinteresse pelos efeitos decorrentes. Espera-se fornecer subsídios que contribuam para remediar ineficiências relacionadas à gestão de resíduos, buscando desencadear ações que possam ser implementadas no âmbito normativo ambiental para as medidas compensatórias e mitigadoras, possibilitando maior desenvolvimento regional e valorização das pequenas propriedades com fortalecimento contínuo do desenvolvimento sustentável.

Palavras-chave: Glicerol. Gestão de resíduos. Lacuna normativa. Sustentabilidade. Riscos e oportunidades.

\title{
ANALYSIS OF GLYCEROL MANAGEMENT: RISKS AND OPPORTUNITIES REGARDING ITS DESTINATION IN RELATION TO THE NORMATIVE LACUNA AND SUSTAINABLE ASPECTS
}

\begin{abstract}
The National Biodiesel Production Program (PNPB) sought to disseminate 'sustainability' with the implementation of biodiesel in the Brazilian energy matrix, therefore, it is assumed an adequate management of its waste. Among them, there is glycerol, which was disregarded, even, by the National Solid Waste Policy (PNRS). Their disposal or misuse in the chemical or food industries can cause health problems for the population. In this scope and interdisciplinary, the objective of this study was to analyze risks and opportunities on the destination of glycerol in front of the normative gap and the sustainable aspects. This is a multi-case study with qualitative methodology and Maxqda ${ }^{\circledR}$ software application for content analysis. The results point to some alternatives of destination, but which are weakened by lack of information and regulation. This fragility is identified mainly by the transfer of responsibility from the big producers to third parties in relation to the destination of glycerol and, above all, disinterest in the resulting effects. It is hoped to provide subsidies aimed at remedying inefficiencies related to waste management, seeking to trigger actions that can be implemented in the environmental normative framework for compensatory and mitigating measures, allowing greater regional development and valuation of small properties, with the continuous strengthening of the sustainable development.
\end{abstract}

REAd | Porto Alegre - Vol. 24 - No 3 - Setembro / Dezembro 2018 - p. 217-243 
Keywords: Glycerol. Waste Management. Regulatory gap. Sustainability. Risks and opportunities.

\section{ANÁLISIS DE LA GESTIÓN DEL GLICEROL: RIESGOS Y OPORTUNIDADES SOBRE SU DESTINO FRENTE A LA LAGUNA NORMATIVA Y ASPECTOS SOSTENIBLES}

\section{RESUMEN}

El Programa Nacional de Producción del Biodiesel (PNPB) buscó difundir 'sostenibilidad' con la implantación del biodiesel en la matriz energética brasileña, por lo tanto, se presupone una adecuada gestión de sus residuos. Entre ellos, hay el glicerol, que fue desconsiderado, inclusive, por la Política Nacional de Residuos Sólidos (PNRS). Su descarte o uso indebido en las industrias químicas o alimenticias puede causar problemas a la salud de la población. En este ámbito e interdisciplinario, el objetivo de este estudio fue analizar riesgos y oportunidades sobre la destinación del glicerol frente a la laguna normativa ya los aspectos sostenibles. Se trata de estudio de múltiples casos con metodología cualitativa y aplicación del software Maxqda ${ }^{\circledR}$ para los análisis de contenido. Los resultados apuntan algunas alternativas de destino, pero que constituyen modos fragilizados por falta de información y reglamentación. Se identifica tal fragilidad, principalmente, por la transferencia de responsabilidad de los grandes productores a terceros en relación al destino del glicerol y, sobre todo, desinterés por los efectos que surgen. Se espera proporcionar subsidios que tengan por objeto remediar ineficiencias relacionadas con la gestión de residuos, buscando desencadenar acciones que puedan ser implementadas, en el ámbito normativo ambiental, para las medidas compensatorias y mitigadoras, posibilitando un mayor desarrollo regional y valorización de las pequeñas propiedades, con el fortalecimiento continuo desenvolvimiento sustentable.

Palabras clave: Glicerol. Gestión de Residuos. Lacuna normativa. Sostenibilidad. Riesgos y oportunidades. 


\section{INTRODUÇÃO}

Pelos incentivos ao uso de fontes renováveis de energia, diversas são as pesquisas realizadas sobre o biodiesel (CONIGLIO et al., 2014; AL-LAL et al., 2012; MARCHETTI; MIGUEL; ERRAZU, 2007). Em 2008, no Brasil, foi criado de um mercado nacional com o Programa Nacional de Produção do Biodiesel (PNPB), que teve início com as discussões internacionais sobre as políticas a serem adotadas em relação aos aspectos socioambientais de sua produção (BAILEY, 2008; NOVI et al., 2013). Dessa forma, no intuito de promover tanto o desenvolvimento regional como a inclusão social, o Governo Federal buscou incentivar seu uso e produção.

De acordo com Quintella et al. (2009) e Freitas (2004), o biodiesel como fonte renovável remete à redução da emissão de gases de efeito estufa e ao desenvolvimento regional. O Brasil figura em segundo lugar no ranking mundial de produção e consumo de biodiesel, onde os Estados Unidos ocupam a primeira posição. Em 2015, foram produzidos 3,4 bilhões de litros de biodiesel e o seu consumo sofreu um aumento de $16,7 \%$.

Um marco regulatório foi obtido pela instituição da Lei nº 11.097 (BRASIL, 2005), que definiu percentuais anuais a serem cumpridos de adição de biodiesel ao óleo diesel. Logo, para seguir as diretrizes impostas pela PNPB, houve um aumento na produção. Entretanto, para a realização dessa atividade econômica fundamental - a produção, são gerados efluentes e resíduos (ROSSETTI, 2016; SALGADO JUNIOR et al., 2014).

O termo glicerol é um resíduo da produção de biodiesel e designa a produção de glicerina bruta (ANP, 2016). Não há dispositivos legais sobre a destinação desse resíduo e, o controle de descarte de efluentes industriais, geralmente, é das Secretarias Estaduais de Meio Ambiente (MACHADO et al., 2012).

Assim, mediante as diretrizes impostas pela PNPB, destaca-se a importância de discutir e apresentar essa problemática, sobretudo, para contribuir em relação à saúde coletiva, pois, o descarte indevido desse resíduo ou mesmo sua aplicação nas indústrias químicas ou alimentícias pode vir a comprometê-la (QUISPE; CORONADO; CARVALHO JR, 2013; ARAÚJO et al., 2013; DALIAS; POLYCARPOU, 2014; OLIVEIRA et al., 2011; CUBAS et al., 2010; FDA, 2006; MIGUEL; MANTOVANI; NOGUEIRA, 2009). Caso incinerado, por exemplo, o glicerol libera uma substância de caráter cancerígeno, a acroleína (BATISTA, 2007).

Diversas críticas em relação aos efeitos decorrentes de um empreendimento devem incluir a área da saúde. Destaca-se que, para promover o crescimento econômico diversas 
atividades são necessárias e, muitas delas, podem acarretar os impactos ambientais, sendo suas consequências demandantes de medidas preventivas. Nesse contexto, em relação à produção ou destinação do seu resíduo glicerol, pressupõe-se a ausência de mecanismos de controle ou fiscalização. Assim, considera-se um fenômeno a ser estudado o fato desse impasse representar um problema, principalmente, para a saúde da sociedade.

Independentemente do setor, as normas ambientais deverão ser seguidas pelos produtores, buscando alternativas para se adequar (BADAJIDE, 2013). No entanto, como se deve tomar decisões frente a ausência de um sistema para incentivar, facilitar ou disciplinar uma atividade? Os custos e benefícios deverão ser comparados mediante as diferentes alternativas decisórias, sejam de natureza econômica ou social (SALGADO JUNIOR; CARLUCCI; NOVI, 2014).

Outra questão é se os produtores de biodiesel têm ciência sobre o risco a que estão expostos o ambiente e a saúde das pessoas diante da grande quantidade de glicerol gerado, tornando-se um problema. Verifica-se que, em dois estados da região nordeste do país, já ocorreram lançamentos glicerol em cursos d'água (FAIRBANKS, 2009). Complementarmente, fato é que houve rejeição de proposta para formulação de políticas públicas para contribuírem junto às pequenas usinas produtoras.

Dentre as aplicações do glicerol exige-se o grau de pureza acima de 95\%, que é obtida em processo de refino (KONGJAO; DAMRONGLERD; HUNSOM, 2010; CONTRERASANDRADE et al., 2015). Não envolve tecnologias complexas, mas seu custo é considerado elevado (OLIVEIRA et al., 2011; DALIAS; POLYCARPOU, 2014) e, portanto, considerada inviável para pequenos e médios produtores de biodiesel. A glicerina bruta está impregnada de excessos de álcool e de impurezas, somente após ser purificada poderá ser utilizada na área química e alimentícia.

Em 2016, as exportações brasileiras de glicerina sofreram queda de mais de $11 \% \mathrm{em}$ relação a 2015, resultando em apenas 270,2 mil toneladas. Assim, segundo Beatriz, Araújo e Lima (2011), é importante buscar alternativas para o volume excedente de glicerol.

Nesse contexto, o objetivo deste estudo foi analisar riscos e oportunidades da destinação do glicerol diante da lacuna normativa. Espera-se que os resultados possam fornecer subsídios para a implantação de políticas que auxiliem a remediar ineficiências sobre a problemática abordada, principalmente, relacionadas às aplicações e implicações à saúde da população. 


\section{DIMENSÕES ECONÔMICA E JURÍdICA: FALHAS DE MERCADO E EXTERNALIDADES}

O impacto que as ações de uma pessoa têm sobre o bem-estar de outras, mesmo que estas não participem da ação, pode ser considerada uma externalidade. Caso esteja presente uma externalidade, não haverá uma distribuição de recursos de maneira eficiente, porque não serão considerados os custos de negociação ou de transação. Um agente econômico inimputável pelas externalidades negativas que causa, produzirá mais do que é socialmente desejável.

As falhas de mercado ocorrem quando a presença de ineficiência gera a necessidade de regulação por parte do Estado, sendo socialmente indesejável os resultados econômicos apresentados. Ocorrendo essas falhas, com a finalidade de promoção do bem-estar social, é necessária uma regulação.

Caso "não devidamente tratada, mesmo em um mercado competitivo, elas impedirão que a máxima eficiência econômica seja alcançada, sob a ótica social, havendo sempre uma divergência entre valores sociais e privados" (PONCIANO; SOUZA; MATA, 2008, p. 3).

Destaca-se que o termo eficiência é também empregado e discutido em diversas áreas do conhecimento, inclusive, utilizando técnicas em métodos quantitativos (SALGADO JUNIOR; NOVI, 2015; COLUCCI; SALGADO JUNIOR, 2015; NOVI, 2017; SALGADO JUNIOR et al., 2014; CLEMENTE et al., 2018; SALGADO JUNIOR et al., 2017; HALLAK REGALO et al., 2016).

Neste estudo, utiliza-se o termo eficiência para designar o uso otimizado de recursos abrangidos pelas externalidades que, segundo Vasconcellos e Garcia (2014, p. 35) "se observam quando a produção ou o consumo de um bem acarreta efeitos positivos ou negativos sobre outros indivíduos ou empresas, que não se refletem nos preços de mercado". Como exemplo, tem-se que as leis antipoluição e de proteção ambiental estão amparadas pelas bases econômicas sustentadas pelas externalidades. "Apercebendo-se da insuficiência dos tradicionais instrumentos de análise da legislação, os juristas passaram a recorrer à Economia como método de estudo e aferição da eficiência da legislação" (PIMENTA, 2006, p. 168).

Quando presentes as externalidades, pressupõe-se que as políticas públicas poderão remediar a ineficiência acarretada pela escassez e pela imperfeição na alocação e aplicação dos recursos (MANKIW, 2016). Tem-se como externalidade um efeito decorrente de transações entre A e B que afetam um terceiro e, a poluição, constitui um exemplo clássico 
(ROSSETTI, 2016; PINHEIRO; SAADI, 2005; VASCONCELLOS; GARCIA, 2014). Esse tipo de efeito é chamado de externalidade negativa, onde se considera que, em um mercado, as situações socialmente ótimas estão abaixo das situações em equilíbrio.

Para suprir as ineficiências decorrentes das externalidades, diversas políticas são utilizadas (MOCHÓN, 2007). Além disso, recomenda-se “considerar não só os efeitos imediatos de qualquer ato ou política, mas, também, os mais remotos; descobrir as consequências dessa política, não somente para um único grupo, mas para todos eles" (HAZLITT, 2010, p. 24). Em sua maioria, as políticas públicas tendem a buscar regulamentar padrões de conduta a serem seguidas, remediando ações socialmente ineficientes. Desse modo, pode-se internalizar uma externalidade tanto com impostos corretivos como licenças de poluição. Segundo Mankiw (2016), em alguns casos as pessoas influenciadas pelas externalidades solucionam seus problemas no âmbito privado, não envolvendo custos de negociação e considerando uma alocação eficiente de recursos.

Sobre falhas de mercado e de governo, corrobora Salama (2008, p. 41) afirmando que "a existência de falhas de mercado é a justificativa clássica para a regulação de atividades pelo Estado. [...] geralmente coexistem com falhas de regulação". Nos Trabalhos desenvolvidos por Matias e Belchior (2007), Ponciano, Souza e Mata (2008) e Coelho (2007) pode-se observar uma análise interdisciplinar relacionada aos conceitos jurídicos e econômicos que envolvem essa temática. Para Costa e Nogueira (2015, p. 91), “custos de transação estão associados às contratações são, portanto, dispêndios de recursos com planejamento, adaptação e fiscalização que envolvem uma negociação ou cumprimento de um contrato".

Conforme explicam Matias e Belchior (2007), há a possibilidade de realizar transações de externalidades de cunho particular sem prejuízo para o ambiente ou para as partes envolvidas, desde que pautadas no princípio da auto regulação de mercado e com desempenho semelhante a uma licença (de poluição). "Sendo assim, de certa forma pode ser imperioso estabelecer parâmetros para atingir um equilíbrio. E isso demanda, muitas vezes, normatização do comportamento" (NOVI, 2017, p. 41).

\section{DIMENSÕES SOCIOAMBIENTAL E JURÍDICA: MEDIDAS COMPENSATÓRIAS E MITIGADORAS}

Segundo Pinheiro e Saadi (2005, p. 11), “há um amplo reconhecimento [...] de que as leis [...] e o direito em geral exercem um papel essencial na organização da atividade REAd | Porto Alegre - Vol. 24 - No 3 - Setembro / Dezembro 2018 - p. 217-243 
econômica". Na presença de externalidades, as políticas públicas podem remediar a ineficiência ocorrida pela imperfeição na alocação e aplicação dos recursos do mercado, pois, "se quiser saber como a economia será afetada por qualquer acontecimento ou política, você precisa pensar, primeiro, nos impactos provocados sobre a oferta e a demanda" (MANKIW, 2016, p. 63).

Existe uma relação direta entre o mercado de glicerol e a produção de biodiesel, portanto, quando há o excesso de oferta, ocorre sua desvalorização (CIRIMINNA et al., 2014; QUISPE; CORONADO; CARVALHO JUNIOR, 2013).

Para Mochón (2007), de acordo com alguns economistas são imprescindíveis o controle e a mediação do Estado. A própria justificativa para a atuação do Estado na seara do direito ambiental é oferecida pela análise econômica, a partir dos modelos de Artur Cecil Pigou e de Ronald Coase. Zylbersztajn e Sztajn (2005, p. 3) enfatizam que "o Direito influencia e é influenciado pela Economia, e as Organizações influenciam e são influenciadas pelo ambiente institucional". Conforme o entendimento desses pesquisadores, analisar interdisciplinarmente algumas questões propicia um conhecimento aprofundado em relação à complexidade da realidade. Com isso, pode-se discutir temas de interesse social, de forma crítica.

Entretanto, abordar problemas ambientais no âmbito da economia atribui o "papel de vilãs" a que foram relegadas nos últimos anos as empresas. Desde a produção até a destinação final, há uma série de problemas envolvendo os resíduos, pois acarretam a poluição (NOVI et al., 2013). Nesse sentido, "a tomada de decisão para a alocação eficiente de recursos em uma sociedade ultrapassa a fronteira estritamente econômica, pois nem tudo que é viável do ponto de vista da economia, é necessariamente bom para o homem" (PONCIANO; SOUZA; MATA, 2008, p. 3).

“Os pilares sustentáveis, constituídos para embasar os interesses da sociedade, estão alicerçados em um terreno complexo e dinâmico onde há um paradoxo entre teoria e prática" (NOVI, 2017, p. 25). Dentre os socioeconômicos, norteiam-se os aspectos inerentes ao bemestar, geração de renda e oportunidades de negócios, já que se considera a produção como atividade fundamental (ROSSETTI, 2016; SALGADO JUNIOR; CARLUCCI; NOVI, 2014). No pilar ambiental estão alicerçados os parâmetros do que se considera como certo e errado frente às demandas dos agentes econômicos.

Dessa forma, está presente um antagonismo nos sistemas produtivos, ambientais e mercadológicos, vez que há divergências nos parâmetros administrativos e de gestão dos recursos (GRAYMORE; SIPE; RICKSON, 2010; ROSSETTI, 2016). Em relação aos 
impactos resultantes da atividade a ser executada, são estabelecidas medidas mitigadoras e compensatórias visando reduzir e compensar os efeitos do impacto, respectivamente (SANTOS et al., 2012). Medidas compensatórias tentam equilibrar perdas ou inconvenientes atuais ou futuros, por exemplo, instituição de políticas públicas relacionadas a projetos de educação ambiental. Já "medidas mitigadoras são o conjunto de procedimentos metodológicos capazes de minimizar e/ou evitar: os efeitos difusos dos impactos negativos da atividade licenciada; o agravamento de impactos identificados e; a ocorrência de novos impactos" (SERRÃO, 2013, p. 24).

Para exemplificar medidas mitigadoras, têm-se a separação do lixo doméstico, reutilização da água de irrigação e curso de capacitação de mão-de-obra, ou seja, atitudes que devem prevenir impactos ou reduzir os que não se pode evitar. Medidas compensatórias podem ser considerados curso de educação ambiental, plantio de árvores nativas e reflorestamento. Estas, visam compensar impactos ambientais, por meio de ações "tomadas voluntariamente pelos responsáveis por esses impactos ou exigidas pelo órgão ambiental competente. Destinam-se a compensar impactos irreversíveis e inevitáveis" (FARIA, 2008, p. $10)$.

De acordo com o Sebrae (2014, online), "no processo de formulação de políticas públicas, a primeira providência a ser tomada quando uma situação é vista como problema [...] é definir as linhas de ação que serão adotadas para resolver a questão". O processo de elaboração de políticas públicas, em geral, segundo essa organização, deverá seguir os trâmites de conversão de estatísticas em informação relevante para o problema, análise das preferências dos atores, ação baseada no conhecimento adquirido.

\section{MÉTODO}

Buscar e propor soluções diante de problemáticas ambientais pressupõe uma interdisciplinaridade, principalmente, considerando a esfera normativa (NOVI et al., 2013). Parte-se do seguinte pressuposto: os agentes poderão negociar sobre uma alocação eficiente de recursos desde que presentes baixos custos de transação, pois, existe a falha de regulação que não lhes impõem condutas em relação à destinação do glicerol. Para tanto, utilizou-se uma abordagem interdisciplinar que envolveu as áreas das ciências jurídicas, econômicas e de gestão. Igualmente, os riscos e as oportunidades foram analisadas levando em conta os aspectos sustentáveis (econômico, ambiental, social), além do legal e tecnológico. 
O método empregado para tratamento e análise dos dados foi análise de conteúdo, por meio do software MAXQDA12 ${ }^{\circledR}$ versão 12.3.1, disponibilizado pela VERBI Software. Consult. Sozialforschung. GmbH Berlin, Germany. Os riscos e oportunidades tiveram como fundamentos e análises as alternativas realizadas pelos produtores de biodiesel e restrições para a aplicação do glicerol, segundo dados coletados ao longo da pesquisa (PEREIRA; SILVA; CARBONARI, 2011; ZENATTI, 2011).

Em relação aos grandes produtores, as informações têm um caráter de parcialidade em sua publicidade, pois são disponibilizadas por empresas privadas que demandam recursos para tal. Em relação aos pequenos, sequer há controle ou base de dados. Portanto, utilizou-se de dados secundários buscando apresentar, ainda que parcialmente, a problemática em relação à $\mathrm{PNPB}$, sobretudo, à implicação à saúde das pessoas.

Foram analisados quatro grandes produtores. Nestes, por julgamento e conveniência com base na sua localização geográfica, foi realizada pesquisa de campo além de visita à uma usina de refino. Já em relação aos pequenos produtores, não há controle sobre os que produzem biodiesel, inclusive, há equipamentos para produção em menor escala disponíveis para compra e venda. Dessa forma, foram identificadas por meio de fontes secundárias duas pequenas unidades produtoras onde, inclusive, as práticas realizadas foram replicadas para 20 outros produtores, junto à uma cooperativa.

\section{ANÁLISE E DISCUSSÃO DOS RESULTADOS}

Diante da ineficiência e da carência de fiscalização sobre algumas empresas e agentes econômicos, as práticas sustentáveis diversas vezes deixam de ser realizadas. Com isso, de acordo com Novi (2017, p. 111), "a problemática existente em relação à degradação ambiental e a função do ordenamento jurídico em regulamentar as questões econômicas ao longo dos anos é demasiado relevante". Sendo assim, sem controle sobre a produção e a destinação do glicerol realizadas, observa-se uma ineficácia normativa da legislação ambiental, onde a integração entre o conhecimento do mercado e a gestão são insuficientes.

Analisar o fator regulamentação é de extrema importância e condizente com as atuais aspirações da sociedade, posto que é relevante a discussão a respeito da sustentabilidade das alternativas de gestão voltadas ao uso racional dos recursos que o ambiente proporciona. Nesse contexto, foram identificados documentos denominados "Fichas de emergência", "Ficha de informações de segurança de produto químico", apenas, em relação ao resíduo glicerol, ou mesmo, o termo glicerina.

REAd | Porto Alegre - Vol. 24 - No 3 - Setembro / Dezembro 2018 - p. 217-243 
Em relação ao transporte do glicerol, realizado por meio de caminhões entre a usina produtora e a usina de refino, pode ser identificado que são utilizadas fichas de informações ou de segurança. Apesar delas seguirem padrões similares, há a presença implícita da lacuna normativa em relação à destinação em seu texto normativo.

Durante a realização deste estudo, o país possuía 55 usinas autorizadas a produzir e comercializar o biodiesel pela Agência Nacional de Petróleo, Gás natural e Biocombustíveis (ANP). De acordo com valores anuais estimados de produção, segundo os dados coletados em apenas uma das usinas pesquisadas, foram cerca de 378 milhões de litros de biodiesel e, portanto, durante esse período, estima-se que a quantidade de glicerol gerada foi de aproximadamente 54 mil toneladas. Esta informação é relevante, pois se trata do volume de glicerol gerado apenas por uma delas.

Conforme dados coletados, todos os grandes produtores vendem, ou 'transferem a destinação' do glicerol para terceiros que, 'revendem' o resíduo glicerol purificado, em sua maioria, para o mercado asiático. Ao final, há o emprego desse resíduo purificado (glicerina) em alimentos, ração animal, cosméticos, fármacos (LEONETI; ARAGÃO-LEONETI; OLIVEIRA, 2012; TAN; AZIZ; AROUA, 2013).

$\mathrm{Na}$ comunidade científica, pesquisadores afirmam e enfatizam que a ausência de planejamento em relação ao excedente de glicerol gerado pela produção de biodiesel constitui uma problemática. Em 2012, já se destacava o problema do alto volume de glicerol gerado, tendo atingido cerca de 260 mil toneladas, volume quase oito vezes superior à demanda. Em 2016, houve uma redução de $11 \%$ na exportação de glicerina em relação ao ano anterior.

Paralelamente, o mercado do glicerol tem poucos estudos que analisam ou discutem sobre o tema, conforme pode ser identificado. As pesquisas sobre esse resíduo parecem estar mais focadas em melhorias nos processos de produção ou mesmo em questões inviáveis na prática e não em problemas sobre aplicações usuais em menor escala, volumes excedentes.

Outra consideração é que, mesmo diante de avanços tecnológicos que permitam estudos sobre a aplicação do glicerol, pode-se verificar que há pouca credibilidade sobre o processo de purificação pelo qual passou esse resíduo antes de ser utilizado em alimentos ou outras áreas.

As pesquisas de utilização do glicerol têm avançado em relação à dieta de animais, sendo um dos pesquisadores entrevistados afirmou que, de modo geral, alguns desses avanços têm sido tornar os animais mais resistentes ao metanol residual presente no glicerol.

Em relação aos impactos ambientais negativos, identificados por meio de fontes secundárias, destaque para casos de descarte indevido/inadequado como os excedentes de 
glicerol, os quais estavam sendo despejados no Rio Poti, na cidade de Crateús, no Ceará, uma região produtora de biodiesel.

\subsection{DESTINAÇÃO DO GLICEROL REALIZADA POR GRANDES E PEQUENOS PRODUTORES}

Por não haver um controle efetivo sobre o volume de glicerol produzido tampouco fiscalização, associados às lacunas normativas, resta ao mercado buscar soluções alternativas. Assim, considerando que a destinação inadequada desse resíduo pode representar um problema para a sociedade, verificou-se que podem existir soluções privadas para as externalidades decorrentes.

As empresas de pequeno porte, denominadas PP "X" e "Y", estão localizadas em municípios no interior do estado de São Paulo e do Maranhão. Produzem e comercializam carnes da criação de animais na propriedade. A partir dos resíduos gerados pelo abate (sebo animal), eles obtêm biofertilizante, biogás e biodiesel que são empregados nas propriedades e geram oportunidade de negócios e renda. Em relação às questões sociais, ambas desenvolvem projetos junto à comunidade local também sobre conscientização do descarte indevido de óleo de cocção.

Na PP "X”, o glicerol é reaproveitado na alimentação de animais e na produção de sabões que são utilizados na propriedade ao invés de ser disposto no ambiente, gerando redução nos custos para aquisição desse material.

Já o modelo utilizado na PP "Y" foi replicado em outras 20 propriedades que seguem um modelo de gestão sustentável para o reaproveitamento de resíduos e, em parceria com uma cooperativa, coletam sebo animal para a produção de biodiesel. Por meio de um arranjo produtivo local, ao invés de ser disposto na natureza, o glicerol é reaproveitado para fabricação de sabonetes que são artesanalmente preparados.

Pode-se observar que as formas de reaproveitamento realizadas nessas propriedades evidenciam aspectos sustentáveis. Econômicos, tendo por base a otimização dos seus recursos disponíveis, buscando eficiência na utilização desses recursos. Ambiental, ao minimizar problemas e impactos ambientais causados por sua atividade, buscam resultados financeiros, sem, contudo, prejudicar o meio ambiente. Social, onde se observa uma função social nessas propriedades, por meio de ações que busquem proporcionar benefícios para a comunidade inserida no seu entorno. 
As Figuras 1 e 2 ilustram as atividades realizadas pelas pequenas propriedades rurais PP "X" e PP "Y", respectivamente. A solução privada proposta nessas pequenas propriedades, em relação às externalidades, buscou remediar os riscos e as vulnerabilidades aos quais estavam sujeitos os proprietários. Assim, houve uma negociação com custos baixos de transação ou inexistentes, resultando em um acordo onde os recursos foram alocados eficientemente, pois há reaproveitamento dos resíduos. Há sinergia entre as atividades, criando um equilíbrio entre recursos.

Figura 1 - Esquematização das alternativas de destinação do glicerol realizada por PP "X"

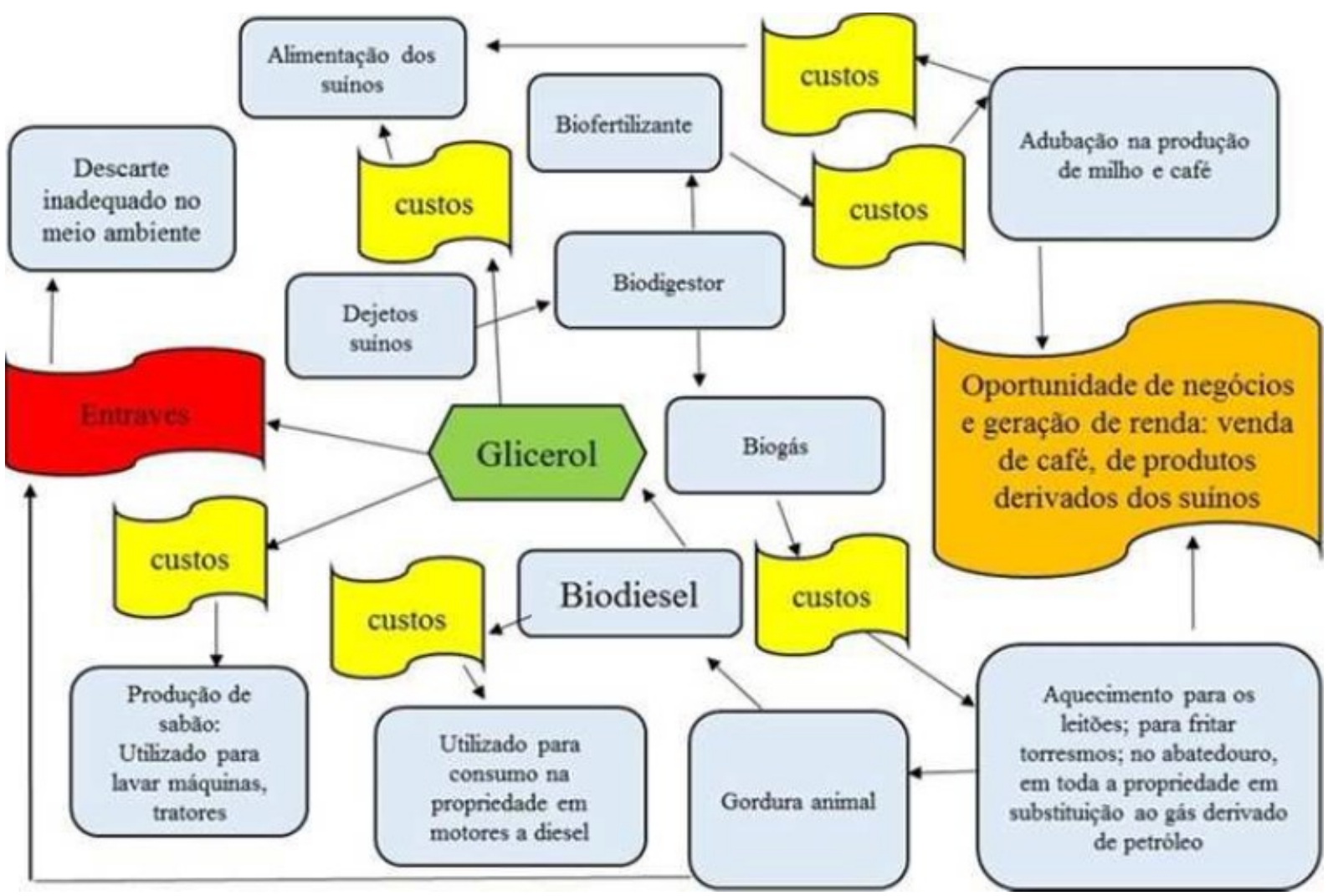

Fonte: elaborado pelos autores. 


\section{Figura 2 - Esquematização das alternativas de destinação do glicerol realizada por PP "Y"}

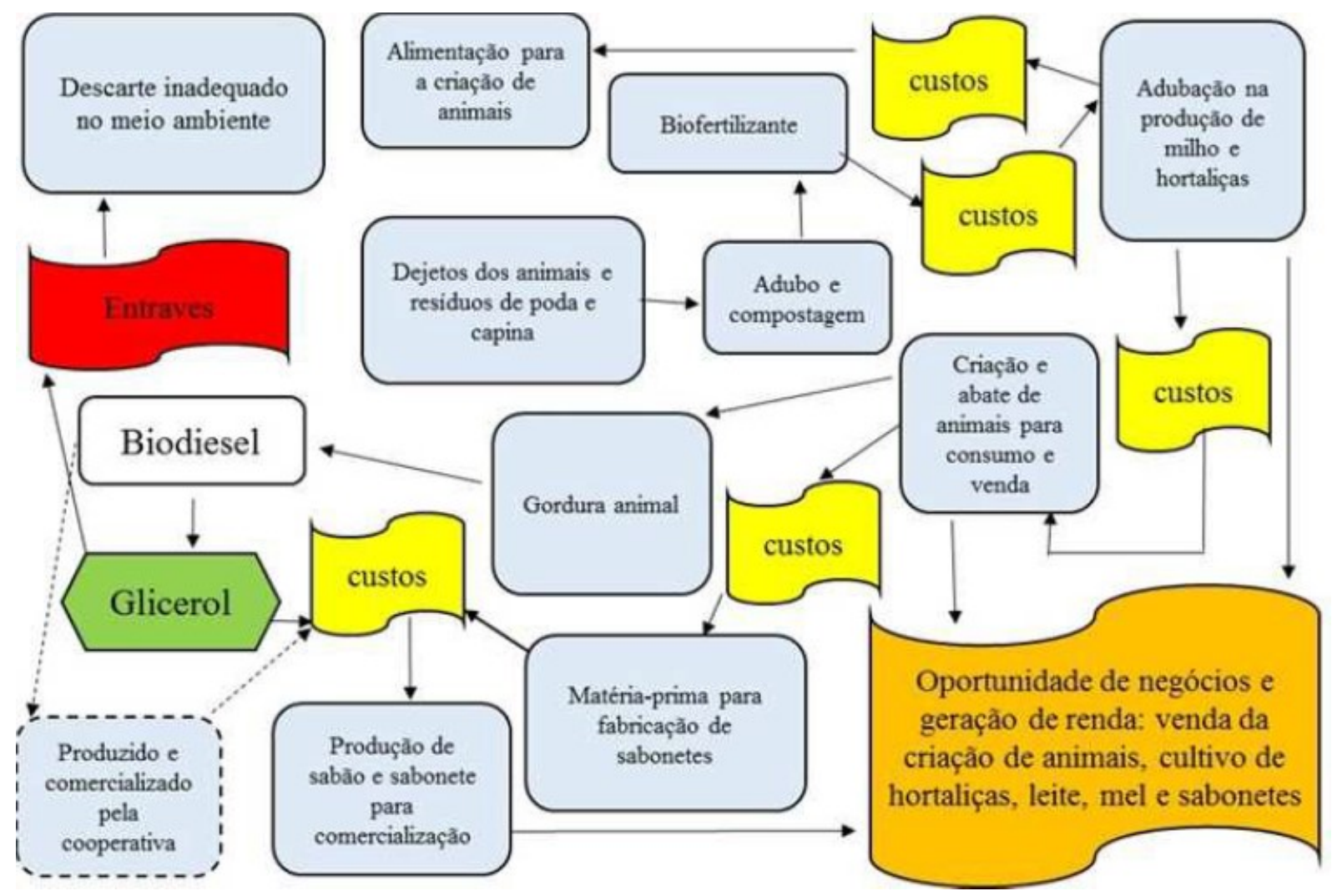

Fonte: Elaborada pelos autores.

O grande produtor pesquisado, considerado "S", está situado num município no interior do estado de São Paulo. Em abordagem preliminar, um fato que merece destaque é que não utiliza biocombustíveis. Em visita técnica realizada, foram observadas e coletadas algumas informações sobre seus processos para a produção de biodiesel e, principalmente, em relação à destinação do glicerol.

Com apontamentos importantes, o que se pode observar em relação ao uso de recursos foi que a usina utiliza a energia elétrica em seus silos de armazenagem dos grãos de soja. Ao ser questionado o responsável disse desconhecer qualquer outra fonte renovável de energia que fosse empregada no processo de secagem do ambiente, para manter os insumos.

Além disso, o aquecimento das caldeiras da usina é feito com o emprego de fontes energéticas lenhosas e uso de biomassa. No caso da produção de biodiesel, há uma determinada quantidade destinada para cumprir as negociações realizadas no mercado nos leilões bimestrais.

O biodiesel produzido é armazenado em tanques dentro da planta da usina e, quando solicitado, é realizado o transbordo para os terminais das distribuidoras de combustível. Em 
relação ao tratamento de efluentes, a água utilizada no processo de lavagem é tratada em uma estação de tratamento de esgoto (ETE) construída na planta da usina para atender exigências da Companhia Ambiental do Estado de São Paulo (CETESB), para que se tenha garantia de conformidade legal no manuseio, transporte, tratamento e destinação da água residual do processo.

O glicerol é vendido e transportado para a usina de refinamento "T", localizada em outro município. O glicerol adquirido por esta usina é proveniente de sebo animal e de soja (de várias partes do Estado de São Paulo e de grandes produtores nacionais). Pode ser observado nesta usina, que vários caminhões estavam descarregando o glicerol, mas tratamse de veículos terceirizados e que não possuem qualquer tipo de sinalização sobre o conteúdo que está sendo transportado, sendo o modal logístico rodoviário.

O material é transportado em caminhões tanque em alta temperatura, para manter seu estado líquido e viscoso, sendo de responsabilidade dos terceiros que realizam seu transporte até a refinaria e não de "S". Pode ser observado que a grande maioria desses caminhões estava em mau estado de conservação e sem qualquer tipo de identificação sobre o conteúdo transportado. Não foi informado quem são as empresas que realizam esse transporte.

Após o refino, a glicerina resultante do glicerol de origem vegetal é exportada para o mercado asiático, via Porto de Santos. Já o glicerol de origem animal, por possuir maior teor de acidez, é revendido, em sua maior parte, como combustível em substituição ao óleo BPF. Este óleo, substitui a lenha nas caldeiras de alguns de seus fornecedores. No entanto, a maioria das caldeiras, inclusive desta mesma refinaria, utilizam a lenha como combustível, por ser 'economicamente mais viável'. Em relação à quantidade produzida, foi informado que o que é produzido é vendido. Sobre legislação ou mesmo riscos e vulnerabilidades há o desconhecimento. A Figura 3, ilustra os processos que foram observados e identificados na produção de biodiesel e destinação de glicerol nas usinas " $S$ " e " $T$ ".

Pode-se observar que há uma 'transferência de responsabilidade' sobre a gestão desse resíduo. Percebe-se os riscos e vulnerabilidades a que está exposta essa ação, pois se trata de um líquido inflamável, que está sendo transportado como produto não classificado como perigoso segundo portaria n. ${ }^{\circ} 291$ de 31 de maio de 1988 do Ministério dos Transportes. 


\section{Figura 3 - Alternativa da destinação do glicerol realizado pelas usinas " $S$ " e "T"}

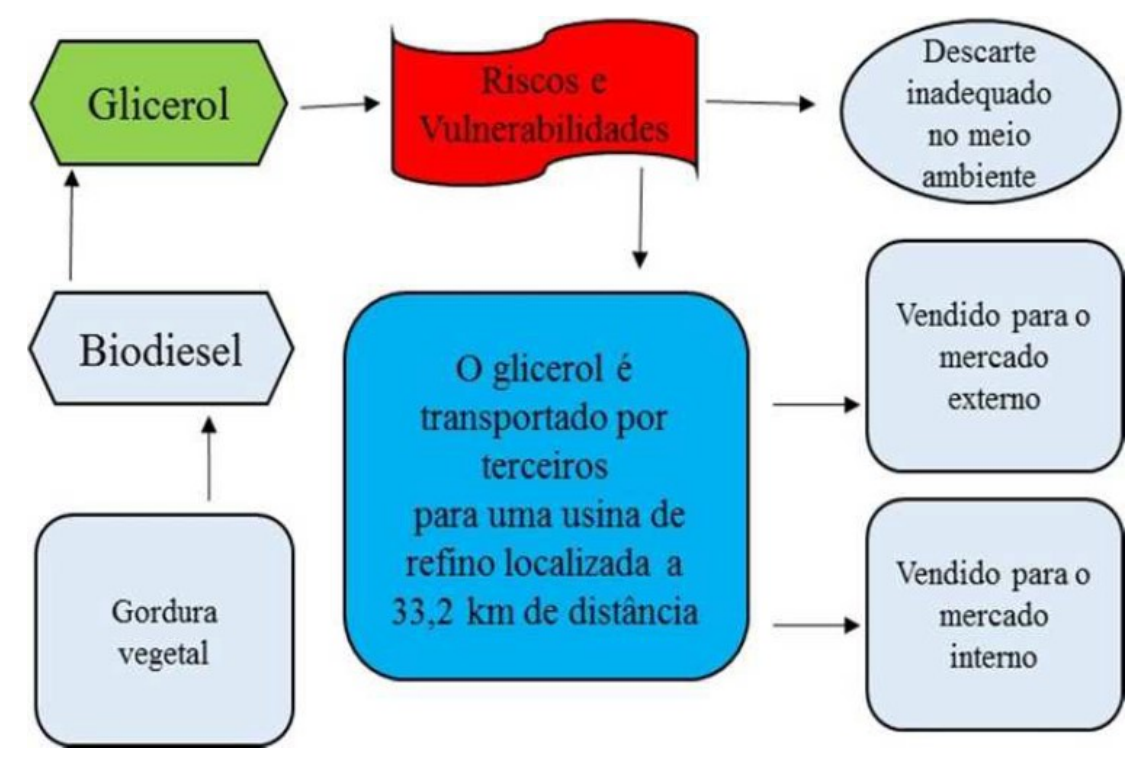

Fonte: elaborado pelos autores.

\subsection{RISCOS E OPORTUNIDADES: DESTINAÇÃO DO GLICEROL E LACUNA NORMATIVA}

Estudos já realizados (QUINTELLA et al., 2009; ROSSETTI, 2016) consideram que a cadeia produtiva do biodiesel deve estar alicerçada em políticas públicas que envolvam esses aspectos, sendo que a codificação dos termos no programa MAXQDA12 ${ }^{\circledR}$ foi realizada conforme adaptações às práticas sustentáveis.

Desse modo, foi gerado um sistema de códigos com base nos dados obtidos dos grandes produtores de biodiesel que permitiu verificar quais frequências predominaram em relação aos impactos ambientais. Pode-se observar que os resultados apresentaram evidências negativas nesse sentido. O total de códigos e segmentos gerados totalizam 18 e 33, respectivamente. Após a codificação, observou-se uma correlação de 46,67\% entre as ações executadas pelos pequenos produtores. Foram 15 e 122 o total dos códigos gerados e o número de segmentos, respectivamente.

Considera-se o pressuposto de baixos custos de transação nas pequenas propriedades. Destacam-se os aspectos econômicos e ambientais, evidenciando a internalização das externalidades identificadas. Ao contrário, em relação aos grandes produtores, ao contrário, presume-se maiores custos de transação e, diante das externalidades, observadas pela maioria de impactos ambientais. Nesse contexto, os pequenos produtores a destinação do glicerol realizada pelos pequenos produtores parece ser eficiente, em termos sustentáveis, conforme categorizações desta pesquisa.

REAd | Porto Alegre - Vol. 24 - No 3 - Setembro / Dezembro 2018 - p. 217-243 
Em relação ao aspecto legal, pode-se verificar que inexistem apontamentos. Assim, restou a esses produtores buscar orientação, fato que aqui foi categorizado como relacionamento com stakeholders. Ao se analisar comparativamente PP "R" e PP "X", pode se observar que em PP "X” houve, primordialmente, a preocupação com o aspecto ambiental. O proprietário salientou por diversas vezes que o motivo principal da reestruturação de seus negócios, de seu planejamento sustentável, foi o incômodo provocado pelos resíduos de animais em sua pequena propriedade.

Posteriormente, a produção de biodiesel foi resultado de orientações externas sobre como destinar a gordura animal provenientes do abate dos animais, assim como, a destinação do glicerol para a produção de sabões utilizados na propriedade ou comercialização de sabonetes. Processos, estes, que podem ter sido propiciados por aspectos tecnológicos.

Os pequenos produtores proporcionam geração de renda e oportunidades de negócios, fazendo com que o aspecto econômico se sobressaia perante os demais. No caso do glicerol, inexiste regulamentação e, portanto, buscou-se orientação junto à stakeholders como forma de incentivo. Por fim, o aspecto social que, apesar de não gerar um número expressivo de empregos frente à quantidade de funcionários e pessoas envolvidas, mas sim, uma oportunidade de fonte de renda familiar, poderá torná-los socialmente excludente em relação ao grande produtor de biodiesel.

Ao final da análise de concordância de intercodificação, entende-se que a abordagem utilizada permitiu observar que, quando presentes baixos custos de transação, os agentes podem negociar sobre a alocação de recursos devido às lacunas normativas que não lhes impõem condutas ou incentivos em relação à destinação do glicerol.

Se é possível a negociação sem custos, então presume-se um acordo em que haja alocação eficiente de recursos, desde que envolvam poucas pessoas. A alocação eficiente dos recursos para o grande produtor talvez poderá demandar maiores custos de transação, o que reforça o fato de se realizar mais pesquisas para aplicações práticas do excedente ou mesmo normatização e controle quanto ao volume gerado.

Nesse contexto, o grande produtor estudado, que sequer faz uso do biodiesel, a responsabilidade sobre a destinação do glicerol é transferida para terceiros. Sua alternativa é vender o glicerol gerado para uma refinaria e ela, então, se revestirá da responsabilidade que lhe caberia.

Uma observação importante é que as formas de destinação realizadas pelos pequenos produtores estudados parecem evidenciar alternativas sustentáveis de gestão do glicerol, com alocação eficiente de recursos. Mesmo que de forma implícita, tais alternativas se pautam no 
que preconiza o artigo $3^{\circ}$, VII, da Política Nacional de Resíduos Sólidos sobre a destinação de resíduos ambientalmente adequada. A produção sustentável de biodiesel requer otimização do seu processo produtivo e reaproveitamento do glicerol gerado.

Por fim, categorizou-se as restrições identificadas em relação à destinação do glicerol conforme os aspectos sustentáveis contemplados neste estudo, além dos legais e tecnológicos. Assim, os riscos identificados na literatura são apresentados no Quadro 1.

\section{Quadro 1 - Aspectos sustentáveis e riscos identificados na literatura}

\begin{tabular}{|c|c|c|}
\hline Aspectos & Riscos & Referências identificadas na literatura \\
\hline \multirow{5}{*}{ Econômicos } & $\begin{array}{l}\text { Dificuldades relativas à comercialização do } \\
\text { glicerol bruto - sem ter sido submetido ao } \\
\text { processo de purificação }\end{array}$ & $\begin{array}{l}\text { Dalias e Polycarpou (2014), Ayoub e } \\
\text { Abdullah (2012), Chi et al. (2007); Tan, } \\
\text { Aziz e Aroua (2013) }\end{array}$ \\
\hline & $\begin{array}{l}\text { Alto custo envolvido no processo de refino ou } \\
\text { purificação }\end{array}$ & $\begin{array}{l}\text { Dalias e Polycarpou (2014), Kongjao, } \\
\text { Damronglerd e Hunsom (2010), Contreras- } \\
\text { Andrade et al. (2015) }\end{array}$ \\
\hline & Oferta e demanda - excesso no mercado & $\begin{array}{l}\text { Quispe, Coronado e Carvalho Junior (2013), } \\
\text { Araújo et al. (2013), Cubas et al. (2010), } \\
\text { Beatriz, Araújo e Lima (2011) }\end{array}$ \\
\hline & $\begin{array}{l}\text { Falhas no processo de refino ou purificação - } \\
\text { baixo teor de pureza }(<95 \%)\end{array}$ & $\begin{array}{l}\text { Araújo et al. (2013), Chi et al. (2007); Tan, } \\
\text { Aziz e Aroua (2013) }\end{array}$ \\
\hline & $\begin{array}{l}\text { Viabilidade econômica de instalação de uma } \\
\text { fábrica de biodiesel deve levar em consideração } \\
\text { a receita obtida com a venda da glicerina } \\
\text { residual }\end{array}$ & Robra et al. (2006) \\
\hline \multirow{3}{*}{ Sociais } & $\begin{array}{l}\text { Em razão da matéria-prima do biodiesel: } \\
\text { glicerol pode causar problemas de saúde }\end{array}$ & Miguel, Mantovani e Nogueira (2009) \\
\hline & $\begin{array}{l}\text { Restrições para inclusão na dieta animal - com } \\
\text { restrições e/ou não recomendado para } \\
\text { ruminantes }\end{array}$ & $\begin{array}{l}\text { Araújo et al. (2013), Dalias e Polycarpou } \\
\text { (2014) }\end{array}$ \\
\hline & $\begin{array}{l}\text { Restrições para inclusão na dieta animal - só } \\
\text { pode ser utilizada quando o resíduo do metanol } \\
\text { na glicerina não ultrapassa } 150 \mathrm{mg} / \mathrm{kg} \text { de } \\
\text { glicerina. }\end{array}$ & $\begin{array}{l}\text { Food and Drug Administration (FDA, } 21 \\
\text { C.F.R. 582.1320, 2006) }\end{array}$ \\
\hline \multirow{4}{*}{ Ambientais } & $\begin{array}{l}\text { Há presença de metanol/etanol em sua } \\
\text { composição }\end{array}$ & $\begin{array}{l}\text { Dalias e Polycarpou (2014), Cubas et al. } \\
\text { (2010), engenheiros químicos e } \\
\text { pesquisadores na área entrevistados }\end{array}$ \\
\hline & $\begin{array}{l}\text { Há presença de material orgânico em sua } \\
\text { composição }\end{array}$ & Cubas et al. (2010) \\
\hline & Descarte indevido em solo ou fontes hídricas & $\begin{array}{l}\text { Dalias e Polycarpou (2014), Araújo et al. } \\
\text { (2013), Oliveira et al. (2011), Fernando et al. } \\
\text { (2007) }\end{array}$ \\
\hline & $\begin{array}{l}\text { Combustão pode liberar poluentes tóxicos, } \\
\text { acroleína }\end{array}$ & Batista (2007) \\
\hline Tecnológicos & $\begin{array}{l}\text { Processo de purificação - inviáveis ou } \\
\text { indisponíveis (desenvolvidos em ambiente } \\
\text { controlado) }\end{array}$ & $\begin{array}{l}\text { Dalias e Polycarpou (2014), Kongjao, } \\
\text { Damronglerd e Hunsom (2010), Contreras- } \\
\text { Andrade et al. (2015) }\end{array}$ \\
\hline \multirow{3}{*}{ Legais } & Reaproveitamento energético & Batista (2007) \\
\hline & $\begin{array}{l}\text { Lacunas normativas - inexiste legislação a } \\
\text { respeito do glicerol }\end{array}$ & $\begin{array}{l}\text { Engenheiros químicos e pesquisadores } \\
\text { entrevistados }\end{array}$ \\
\hline & $\begin{array}{l}\text { Ampliação do uso de biodiesel - normatização } \\
\text { favorável ou não }\end{array}$ & Romero (2013) \\
\hline
\end{tabular}

Fonte: elaborado pelos autores. 
Uma sistematização dos efeitos decorrentes da destinação do glicerol diante da lacuna normativa, sob os riscos e as oportunidades identificadas na pesquisa pode ser observada na Figura 4.

Figura 4 - Riscos e oportunidades frente à lacuna normativa e aspectos sustentáveis

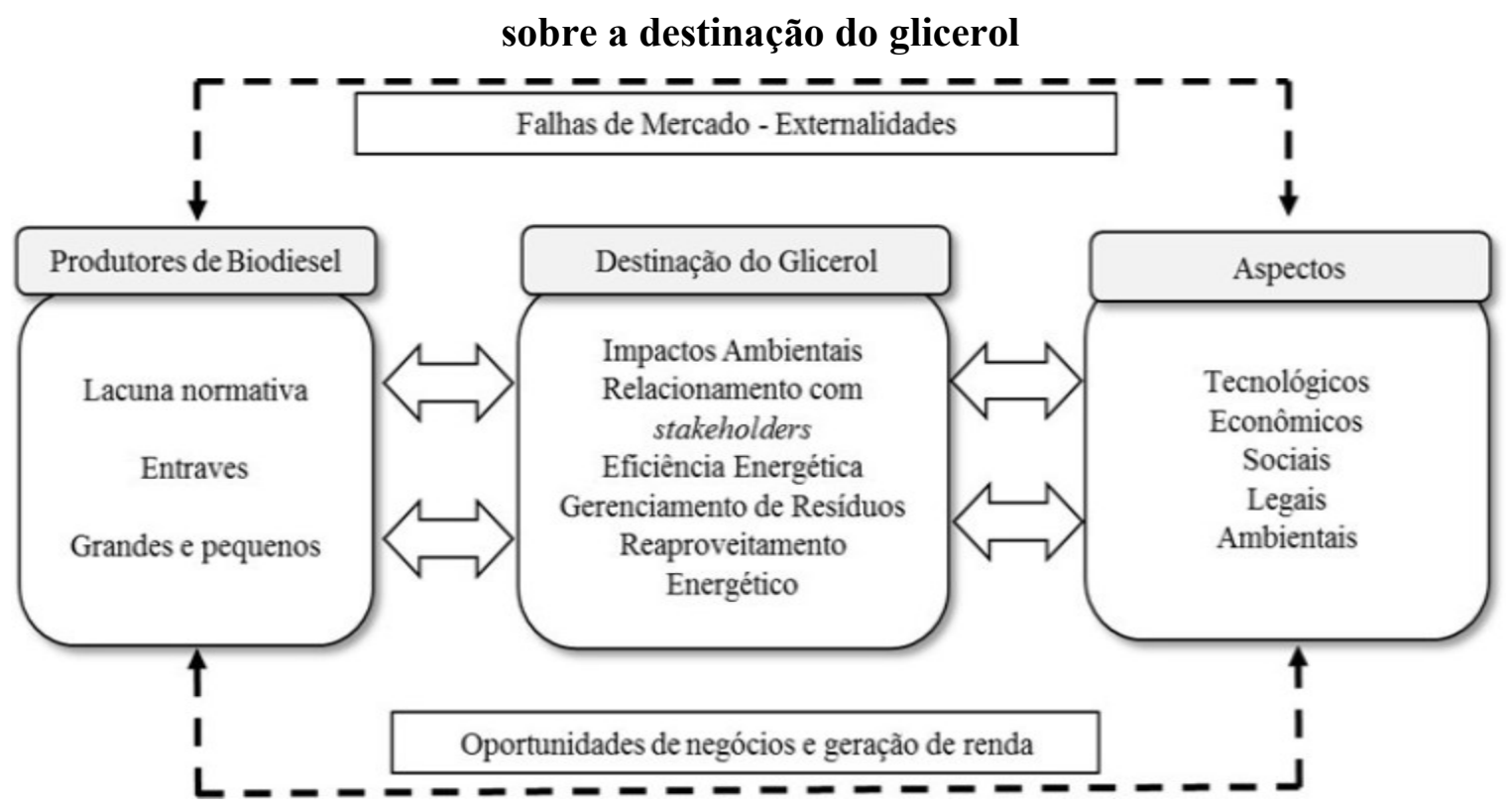

Fonte: elaborado pelos autores.

Em relação à análise da destinação do glicerol sob os aspectos considerados no estudo, destacam-se os apresentados abaixo.

(a) Econômico - o 'lucro' impulsionou a realização de projetos nas unidades estudadas. Sobre a diversificação da produção nas pequenas unidades, por representar oportunidade de geração de renda, negócios e provável redução de custos com o reaproveitamento dos resíduos, pode-se inferir que esse aspecto foi basilar. Entretanto, por meio das alternativas dos pequenos produtores não haverá a geração de um número expressivo de empregos frente à quantidade de funcionários e pessoas envolvidas, mas sim, uma oportunidade de fonte de renda familiar, o que poderá torná-lo socialmente excludente em relação ao grande produtor de biodiesel; Este, conforme apresentado, possui mais de 500 funcionários (FONSECA, 2015; ZENATTI, 2011; GRAYMORE; SIPE; RICKSON, 2010).

(b) Social - os pequenos produtores aproveitaram as oportunidades de conhecimento gerado, no relacionamento com stakeholders, junto a cooperativas, buscando suprir suas necessidades, inclusive, de recursos detentores de conhecimentos específicos. Em ambas, a geração de renda e oportunidades de negócios proporcionou um desenvolvimento sustentável, sob a dimensão social, por desenvolver habilidades junto a comunidades, através da REAd | Porto Alegre - Vol. 24 - No 3 - Setembro / Dezembro 2018 - p. 217-243 
capacitação de pessoas e geração de emprego. Este, pode não ser representativo em relação à um grande produtor, o que o torna excludente, mas é uma forma de proporcionar também desenvolvimento regional (MACHADO et al., 2012; BAYLEI, 2011; HANSSON H; FERGUSON, 2011).

(c) Legal - vinculados ao mercado, a preponderância dos grandes produtores de biodiesel torna a destinação do glicerol estrategicamente insustentável, uma vez que, no caso estudado, parece haver uma transferência de responsabilidade para terceiros diante de lacunas normativas existentes; diante das falhas de mercado e de regulação. Porém, podem e devem servir como base para melhorias futuras, cumprindo, assim, o papel de precursoras de uma realidade a qual poderá ser parte quase unânime do discurso racional no que tange à gestão (ARAÚJO et al., 2013; SALAMA, 2008).

(d) Ambiental - pressupõe-se que, caso não regulamentado, a situação atual sobre a destinação do glicerol poderá permanecer inalterada, pois os benefícios resultantes das alternativas, talvez, demandem investimentos que transcendam a atividade-fim dos grandes produtores; Sem incentivos e disciplina (no caso regulação), os pequenos poderão permanecer sem o apoio governamental (DALIAS; POLYCARPOU, 2014; GRAYMORE; SIPE; RICKSON, 2010).

(e) Tecnológico - os custos dos equipamentos disponíveis, podem não representar prioridades para os grandes produtores investirem em usinas de refino. Muito embora existam várias pesquisas sobre o glicerol, estas são, em sua maioria, pertencentes à área da Química, desenvolvidas em ambientes controlados e, portanto, ou em fases experimentais ou incipientes. Constituem os aspectos mais incertos, pois são mutáveis em relação ao tempo e à indústria, com o caráter obsoleto (QUISPE; CORONADO; CARVALHO, 2013; DALIAS; POLYCARPOU, 2014).

\section{CONSIDERAÇÕES FINAIS}

O objetivo foi analisar os riscos e as oportunidades da destinação do glicerol frente à lacuna normativa e aos aspectos sustentáveis. A PNPB representa um grande avanço na área de produção e uso do biodiesel, mas, em relação ao seu resíduo glicerol, inexistem preceitos tampouco fiscalização que possam controlar efetivamente ou normatizar sua gestão. Desse modo, cabe aos agentes econômicos buscar soluções alternativas. Caso o glicerol seja destinado ou tenha suas aplicações indevidas nas indústrias químicas ou alimentícias pode 
causar problemas à saúde da população. Destaca-se, portanto, a importância e a necessidade de estudos que contemplem essa problemática.

A abordagem utilizada envolveu as áreas das ciências econômicas, jurídicas e de gestão. Dessa forma, observa-se que, uma alocação eficiente de recursos poderá ser negociada pelos agentes, se presentes baixos custos de transação, pois pressupõe-se a existência de uma falha de regulação em relação às condutas realizadas sobre a destinação do glicerol.

Pode-se observar, ante aos dados coletados em relação ao volume de glicerol, que há um excedente no mercado cabendo, para os agentes, a contemplação de soluções alternativas para sua destinação. Nesse sentido, como forma de contribuição para elaboração de políticas públicas, foram analisadas informações ora consideradas relevantes sobre a problemática abordada neste estudo. Assim, destacou-se aspectos que envolvem a destinação do glicerol e a reflexão sobre a possibilidade de problemas, principalmente na área da saúde, que isso pode representar para a sociedade, discutindo falhas de regulação e de mercado, onde se identificou soluções privadas sustentáveis nos casos de externalidades envolvendo pequenos produtores de biodiesel.

Diante das análises das pequenas propriedades infere-se uma possível internalização das externalidades, concernentes entre os entraves e os aspectos sustentáveis. Entretanto, em relação aos grandes produtores, são presumidos maiores custos de transação e, portanto, parece não haver uma internalização que possa ser considerada sustentável.

Como entraves aos aspectos sustentáveis, considerou-se as restrições identificadas por meio de estudos anteriormente realizados sobre os processos de refino aos quais o resíduo deverá ser submetido para ser aplicado, onde passa a ser denominado glicerina. Com isso, alternativas de destinação para o glicerol utilizadas pelos pequenos produtores, em termos sustentáveis, puderam ser evidenciados.

Além disso, ainda em relação aos aspectos sustentáveis analisados no estudo, identificou-se que um deles possui um caráter incerto, o tecnológico. Já no aspecto social discutiu-se sobre o engajamento dos stakeholders, sobretudo, na capacitação e orientação de profissionais da área. No entanto, mesmo que possa promover desenvolvimento regional, envolver trabalhos comunitários promovendo geração de empregos e capacitação profissional pode não ser representativo para os grandes produtores, destacando uma particularidade de ineficiência. $\mathrm{O}$ aspecto econômico sobressai-se perante os demais. 
No intuito de fundamentar a necessidade de políticas públicas, analisou-se o aspecto legal, onde se pode observar a inexistência de normatização, controle ou fiscalização sobre o resíduo.

Dessa forma, o reaproveitamento energético tido como uma das principais alternativas utilizadas pelos pequenos produtores, ao minimizar os impactos ambientais, parecem promover uma sinergia com os stakeholders, pois, além da eficiência energética ainda promovem o que pode se caracterizar como um adequado gerenciamento do resíduo glicerol.

Uma amostra não representativa foi utilizada neste trabalho e, portanto, não generalizável. Contudo, os resultados obtidos possuem relevância no meio acadêmico, uma vez que poucos são os estudos que abordam essa temática. Nesse sentido, algumas limitações privaram um maior aprofundamento, principalmente, relacionadas à base de dados, vez que não localizada nenhuma relacionada aos pequenos produtores e dificuldades no acesso aos participantes da pesquisa.

Como sugestão para futuros trabalhos na área pode-se verificar a existência de projetos sobre o reaproveitamento do glicerol excedente por parte dos grandes produtores, contribuindo para que a produção de biodiesel possa ser socialmente justa e ambientalmente correta, incluindo aspectos de logística e fomentando arranjos produtivos locais. Além disso, buscar observar o interesse do Poder Público sobre o tema.

Espera-se que os resultados possam fornecer subsídios para a implantação de políticas que visem remediar ineficiências relacionadas à sustentabilidade nos negócios. Neste estudo, para atribuir funcionalidade às políticas públicas, o sistema evidenciado poderá incentivar, disciplinar e facilitar ações que possam colaborar na manutenção concomitante de um sistema econômico e proteção ambiental.

Deve-se considerar subsídios, em especial, para o pequeno produtor, que parece não receber orientação e suporte necessário à execução de suas atividades. Assim, complementarmente, em relação ao aproveitamento sustentável do glicerol, esta pesquisa poderá para que o planejamento e a tomada de decisão versem sobre oportunidades de negócios e redução de impactos ambientais. Além disso, auxiliar no aperfeiçoamento do conhecimento já existente envolvendo gestão de resíduos. Por fim, aprimorar a PNPB, auxiliando no âmbito das medidas compensatórias e mitigadoras, para que o desenvolvimento regional e valorização das pequenas propriedades sejam incrementados, conjuntamente ao desenvolvimento sustentável. 


\section{REFERÊNCIAS}

AGÊNCIA NACIONAL DO PETRÓLEO, GÁS NATURAL E BIOCOMBUSTÍVEIS ANP. Anuário estatístico brasileiro do petróleo, gás natural e biocombustíveis: 2016. Rio de Janeiro: ANP, 2016.

AL-LAL AM, GARCÍA-GONZALEZ JE, LLAMAS A, MONJAS A, CANOIRA, L. A new route to synthesize tert-butyl ethers of bioglycerol. Fuel, v. 93, p. 632-637, 2012.

ARAÚJO, A. R.; RODRÍGUEZ, N. M.; COSTA, H. H. A.; SILVA, V. L. Glicerol na alimentação de ruminantes. Ciência Animal, v. 23, n. 1, p. 20-25, 2013.

AYOUB, M.; ABDULLAH, A. Z. Critical review on the current scenario and significance of crude glycerol resulting from biodiesel industry towards more sustainable renewable energy industry. Renewable and Sustainable Energy Reviews, v. 16, p. 2671-2686, 2012.

BADAJIDE, O. Sustaining Biodiesel Production via Value-Added Applications of Glycerol. Journal of Energy, p. 1-7, 2013.

BAILEY, R. Another Inconvenient Truth: How biofuel policies are deepeningpoverty and accelerating climate change. In: Oxfam Policy and Practice: Climate Change and Resilience, v. 4, n. 2, p. 1-58, 2008.

BATISTA, F. Brasil não tem destino certo para glicerina gerada por biodiesel. 2007.

Disponível em: https://www.biodieselbr.com/noticias/biodiesel/brasil-destino-certo-glicerinagerada-biodiesel-05-06-07.htm. Acesso em: 14 mai. 2018.

BEATRIZ, A.; ARAÚJO, Y. J. K.; LIMA, D. P. Glicerol: um breve histórico e aplicação em sínteses estereosseletivas. Química Nova, v. 34, n. 2, p. 306-319, 2011.

BRASIL. Lei n. 11.097, de 13 de janeiro de 2005. Dispõe sobre a introdução do biodiesel na matriz energética brasileira. Disponível em: http://www.planalto.gov.br/Ccivil 03/_Ato20042006/2005/Lei/L11097.htm. Acesso em: 1 jul. 2018.

CLEMENTE, L. M.; SALGADO JUNIOR, A. P.; FALSARELLA JUNIOR, E.; SOUZA JUNIOR, M. A.; NOVI, J. C.; DUARTE, A. C. M. Management towards financial sustainability for private health companies. Management Research Review, v. 41, p. 1-1, 2018.

CHI, Z.; PYLE, D.; WEN, Z.; FREAR, C.; CHEN, S. A laboratory study of producing docosahexaenoic acid from biodiesel-waste glycerol by microalgal fermentation. Process Biochemistry, v. 42, n. 11, p. 1537-1545, 2007. 
COLUCCI, L.; SALGADO JUNIOR, A. P. Os perfis das escolas municipais do ensino fundamental eficientes em transformar investimento financeiro em desempenho no IDEB: uma análise DEA. Revista de Educação, Ciência e Cultura, v. 20, p. 45-61, 2015. CONIGLIO L, COUTINHO JAP, CLAVIER JY, JOLIBERT F, JOSE J, MOKBEL I, PILLOT D, PONS MN, SERGENT M, TSCHAMBER V. Biodiesel via supercritical ethanolysis within a global analysis "feedstocks-conversion-engine" for a sustainable fuel alternative. Progress in Energy and Combustion Science, v. 43, p. 1-35, 2014. CONTRERAS-ANDRADE, I.; AVELLA-MORENO, E.; SIERRA-CANTOR, J. F.; GUERRERO-FAJARDO, C. A.; SODRÉ, J. R. Purification of glycerol from biodiesel production by sequential extraction monitored by 1 H NMR. Fuel Processing Technology, v. 132, p. 99-104, 2015.

CUBAS, J. L.; ADÃO, D. C.; FERREIRA, F. A. F.; DELFINO, L. D.; ZAGONEL, G. F.; SILVA, P. R.; MAIA, M.; ADAD, L. B.; VECHIATTO, W. W. D.; SUCHEK, E. M.; COSTA B. J. Neutralização da glicerina bruta obtida pela transesterificação dos óleos de crambe, cárcamo e soja. In: Congresso Brasileiro de plantas oleaginosas, óleos, gorduras e biodiesel, 7., 2010, Belo Horizonte. Anais... Belo Horizonte: UFLA, 2010.

DALIAS, P.; POLYCARPOU, P. Decomposition of the biodiesel by-product, crude glycerol, in soil. Rev. Agr. Eng., v. 60, n. 1, p. 17-23, 2014.

FAIRBANKS, M. Glicerina. Revista Química e Derivados, n. 487, 2009. Disponível em: http://www.dequi.eel.usp.br/ barcza/GlicerinaQuim\&Deriv.pdf. Acesso em: 05 jul. 2018 FERNANDO, S.; ADHIKARI, S.; KOTA, K.; BANDI, R. Glycerol based automotive fuels from future biorefineries. Fuel, v. 86, n. 17-18, p. 2806-2809, 2007.

FONSECA, R. O. Compensação ambiental: da contradição à valoração do meio ambiente no Brasil. Sociedade \& Natureza, v. 27, n. 2, p. 209-222, 2015. FOOD AND DRUG ADMINISTRATION - FDA. 2006. Substances generally recognized as safe: general purpose food additives glycerin. Code of Federal Regulations. 2006. FREITAS, S. M. Biodiesel à base de óleo de soja é a melhor alternativa para o Brasil? Informações Econômicas, v. 34, n.1, 2004.

GRAYMORE, M. L. M.; SIPE, N. G.; RICKSON, R. E. Sustaining human carrying capacity: a tool for regional sustainability assessment. Ecologia Econômica, v. 69, p. 459-468, 2010. HALLAK REGALO, E.; SALGADO JUNIOR, A. P.; NOVI, J. C.; FALSARELLA JUNIOR, E. Melhores Práticas que Podem Contribuir para o Desempenho dos Alunos Brasileiros do Ensino Fundamental. Meta: Avaliação, v. 8, p. 1-28, 2016. 
HANSSON, H.; FERGUSON, R. Factors influencing the strategic decision to further develop dairy production: A study of farmers in central Sweden. Livestock Science. v. 135, n. 2-3, p. 110-123, 2011.

KONGJAO, S.; DAMRONGLERD, S.; HUNSOM, M. Purification of crude glycerol derived from waste used-oil methyl ester plant, Korean Journal of Chemical Engineering, v. 27, n. 3, p. 944-949, 2010.

LEONETI, A. B.; ARAGÃO-LEONETI, V.; OLIVEIRA, S. V. W. B. Glycerol as a byproduct of biodiesel production in Brazil: Alternatives for the use of unrefined glycerol.

Renewable Energy, v. 45, p. 138-145, 2012.

MACHADO, B. A. S.; FIGUEIREDO, T. V. B.; SANTOS, J. C. P.; REIS, J. H. O.;

MARCHETTI, J. M.; MIGUEL, V. U.; ERRAZU, A. F. Possible methods for biodiesel production. Renewable and Sustainable Energy Reviews, v. 11, n. 6, p. 1300-1311, 2007. MIGUEL, A. M. R. O.; MANTOVANI, D. M. B.; NOGUEIRA, R. M. Com mais biodiesel, sobra glicerina e crescem riscos de diarreia. I Seminário sobre Biodiesel e Coprodutos, 2009, Anais... Campinas, SP: ITAL/CCQA, 2009.

NOVI, J. C. Análise das alternativas de destinação do glicerol realizadas por produtores de biodiesel: proposta de contribuição no âmbito das medidas compensatórias e mitigadoras. 2017. Tese (Doutorado em Administração de Organizações) - Faculdade de Economia, Administração e Contabilidade de Ribeirão Preto, Universidade de São Paulo, Ribeirão Preto, 2017.

NOVI, J. C.; OLIVEIRA, S. V. W. B.; SALGADO JUNIOR, A. P.; BONACIM, C. A. G.; OLIVEIRA, M. M. B. Avaliação legal, ambiental e econômica da implantação de sistema próprio de tratamento de Resíduos de Serviços de Saúde para geração de energia em hospitalescola do Estado de São Paulo. Desenvolvimento e Meio Ambiente, v. 27, p. 193-209, 2013. NOVI, J. C.; OLIVEIRA, S. V. W. B.; SALGADO JUNIOR, A. P.; OLIVEIRA, M. M. B. Resíduos de Serviços de Saúde: Pluralidade normativa e questões associadas desde sua geração até a disposição final. Fórum de Direito Urbano e Ambiental, v. 72, p. 41-56, 2013.

OLIVEIRA, S. V. W. B.; LEONETI, A. B.; CALDO, G. M. M.; OLIVEIRA, M. M. B. Generation of bioenergy and biofertilizer on a sustainable rural property. Biomass and Bioenergy, v. 35, n. 7, p. 2608-2618, 2011. PEREIRA, A. C.; SILVA, G. Z. da; CARBONARI, M. E. E. Sustentabilidade, responsabilidade social e meio ambiente. São Paulo: Saraiva, 2011. 
PINTO, B. P.; DE ARAUJO MOTA, C. J. Developments in glycerol byproduct-based biorefineries. Advances in Biorefineries - Biomass and Waste Supply Chain Exploitation, p. 364-385, 2014.

QUINTELLA, C. M.; TEIXEIRA, L. S. G.; KORN, M. G. A; COSTA NETO, P. R.; TORRES, E. A.; CASTRO, M. P.; JESUS, C. A. C. Cadeia do biodiesel da bancada à indústria: uma visão geral com prospecção de tarefas e oportunidades para P\&D\&I. Química Nova, v. 32, n. 3, p. 793-808, 2009.

QUISPE, C. A. G.; CORONADO, C. J. R.; CARVALHO JR, J. A. Glycerol: Production, consumption, prices, characterization and new trends in combustion. Renewable and Sustainable Energy Reviews, v. 27, p. 475-493, 2013.

ROBRA, S.; SANTOS, J. V. S.; OLIVEIRA, A. M.; CRUZ, R. S. Usos alternativos para a glicerina resultante da produção de biodiesel: Parte 2 - Geração de Biogás. In: Congresso Da Rede Brasileira de Tecnologia do Biodiesel. Anais... 1, p. 1-4, Brasília, 2006.

ROMERO, G. A. Uso de biodiesel em motores marítimos para a navegação. Rio de Janeiro: UFRJ/ Escola Politécnica, 2013.

ROSSETTI, J. P. Introdução à economia. 21 ed. São Paulo: Atlas, 2016.

SALAMA BM. O que é pesquisa em Direito e Economia? Uma introdução à epistemologia da disciplina para o estudante, o profissional e o pesquisador em direito. Cadernos Direito GV, v. 5, n. 22, 2008.

SALGADO JUNIOR, A. P.; CARLUCCI, F. V.; BONACIM, C. A. G.; NOVI, J. C.; PACAGNELLA JUNIOR, A. C. Investment potential for new sugarcane plants in Brazil based on assessment of operational efficiency. The International Food and Agribusiness Management Review (Online), v. 17, p. 41-64, 2014.

SALGADO JUNIOR, A. P.; CARLUCCI, F. V.; NOVI, J. C. Aplicação da análise envoltória de dados (AED) na avaliação da eficiência operacional relativa entre usinas de cana-deaçúcar no território brasileiro. Engenharia Agrícola, v. 34, p. 826-843, 2014.

SALGADO JUNIOR, A. P.; NOVI, J. C. Proposta de práticas administrativo-pedagógicas que possam contribuir para o desempenho dos alunos de escolas municipais do ensino fundamental na Prova Brasil. Ensaio, v. 23, p. 631-662, 2015.

SALGADO JUNIOR, A. P.; PIMENTEL, L. A. S.; OLIVEIRA, M. M. B.; NOVI, J. C. O impacto nas variações das matrizes energéticas e uso da terra: estudo sobre a eficiência ambiental do G20. Revista Eletrônica de Administração, v. 23, p. 306-332, 2017. 
SANTANA, M. C. C. B.; DRUZIAN, J. I. Mapeamento tecnológico do glicerol/glicerina sob o enfoque em documentos de patentes depositados no Brasil. Cadernos de Prospecção, v. 5, n. 1, p. 14-22, 2012.

SANTOS, M. E.; LEONETI, A. B.; NOVI, J. C.; OLIVEIRA, S. V. W. B. O ônibus movido a etanol como medida para a mitigação dos gases de efeito estufa no município de São Paulo. In: XI Safety, Health and Environment World Congress. SHEWC'2012, 2012, São Paulo. Proceedings of Safety, Health and Environment World Congress, v. 12. p. 352-356.

TAN, H. W.; AZIZ, A. R.; AROUA, M. K. Glycerol production and its applications as a raw material: A review. Renewable and Sustainable Energy Reviews, v. 27, p. 118-127, 2013. VASCONCELLOS, Y. Resíduos bem-vindos: subproduto do biodiesel pode ser usado para suprimir poeira de vagões de minério. Revista Pesquisa Fapesp, 196, p. 58-63, 2012. ZENATTI, D. C. Tratamento e aproveitamento de resíduos da produção de biodiesel: água residuária e glicerol. 2011. Tese (Doutorado em Engenharia Agrícola) - Universidade Estadual do Oeste do Paraná. Unioeste. Cascavel, Paraná, 2011. 